NBER WORKING PAPER SERIES

\title{
TECHNOLOGY ADOPTION IN AND OUT OF MAJOR URBAN AREAS: WHEN DO INTERNAL FIRM RESOURCES MATTER MOST?
}

\author{
Chris Forman \\ Avi Goldfarb \\ Shane Greenstein \\ Working Paper 11642 \\ http://www.nber.org/papers/w11642 \\ NATIONAL BUREAU OF ECONOMIC RESEARCH \\ 1050 Massachusetts Avenue \\ Cambridge, MA 02138 \\ September 2005
}

Respectively at Carnegie Mellon University, University of Toronto, and Northwestern University. We thank Ashish Arora, Tom Åstebro, Maryann Feldman, Steven Klepper, Brian McManus, Sandra Slaughter, Scott Stern, Will Strange, and many seminar participants for comments. We also thank Harte Hanks Market Intelligence for supplying data. We received funding from the Kellogg School of Management, SSHRC grant \#538-02-1013, and the GM Strategy Center. All opinions and errors are ours alone. The views expressed herein are those of the author(s) and do not necessarily reflect the views of the National Bureau of Economic Research.

(C)2005 by Chris Forman, Avi Goldfarb and Shane Greenstein. All rights reserved. Short sections of text, not to exceed two paragraphs, may be quoted without explicit permission provided that full credit, including $($ ) notice, is given to the source. 
Technology Adoption In and Out of Major Urban Areas: When Do Internal Firm Resources Matter Most?

Chris Forman, Avi Goldfarb and Shane Greenstein

NBER Working Paper No. 11642

September 2005

JEL No. R30, O33, L86

\section{ABSTRACT}

How much do internal firm resources contribute to technology adoption in major urban locations, where the advantages from agglomeration are greatest? The authors address this question in the context of a business's decision to adopt advanced Internet technology. Drawing on a rich data set of adoption decisions by 86,879 U.S. establishments, the authors find that the marginal contribution of internal resources to adoption is greater outside of a major urban area than inside one. Agglomeration is therefore less important for highly capable firms. The authors conclude that firms behave as if resources available in cities are substitutes for both establishment-level and firm-level internal resources.

Chris Forman

Tepper School of Business

Carnegie Mellon University

5000 Forbes Avenue, Posner 386

Pittsburgh, PA 15213

cforman@andrew.cmu.edu

Avi Goldfarb

Rotman School of Management

University of Toronto

105 Saint George Street

Toronto, ON M5S 3E6

CANADA

avi.goldfarb@rotman.utoronto.ca
Shane Greenstein

Kellogg School of Management

Northwestern University

2001 Sheridan Road

Evanston, IL 60208

and NBER

greenstein@kellogg.northwestern.edu 


\section{Introduction}

A large body of evidence confirms there is significant agglomeration in economic activity (Rosenthal and Strange 2003). Businesses in major urban $\operatorname{areas}^{1}$ benefit from access to inputs that improve labor productivity and innovative activity. Organizations with locations outside of major urban areas may try to replicate the resources available within major urban areas, either by moving resources between locations or by making special investments at isolated facilities. If these attempts do not succeed then locating production in a major urban area may shape opportunities to access knowledge essential to innovative activity (Furman, Kyle, Cockburn and Henderson, 2005) and become a source of sustainable competitive advantage (Porter 1998).

The extent of advantage from an urban location is an empirical question. How much do internal firm resources and investment activities substitute for the advantages of economic agglomeration, if they do at all? This question has been difficult to address due to a scarcity of data linking geography, internal resources, and adoption. This paper provides substantial empirical evidence on an important activity in which both locating in a major urban area and mobility of resources have been linked to improvements in innovative activity, namely, the adoption of advanced information technology (IT) by firms.

Two factors set the stage for our study. First, the costs of advanced IT projects are lower for firms with access to rich local resources in major urban areas (e.g., Columbo and Masconi 1995; Forman, Goldfarb, and Greenstein 2005). In addition, prior experience on related projects can create internal capabilities within organizations that reduce the costs to new innovation (Attewell 1992; Cohen and Levinthal 1990; Åstebro 2002). If firms can move these resources for advanced IT projects-either between projects in the same establishment or between establishments in the same organization — then internal resource mobility might make up for the lack of local resources outside a major urban area. ${ }^{2}$

\footnotetext{
${ }^{1}$ We use major urban area, city, and sizeable city interchangeably and, for pragmatic purposes, later define them as a metropolitan statistical area (MSA) that has a population of over 500,000.

${ }^{2}$ We use the terms firm and organization interchangeably. Multi-establishment firms can have establishments in
} 
We focus on the largest investors in IT in the United States. Specifically, we analyze a survey (conducted by Harte Hanks) of adoption of advanced Internet technologies at 86,879 establishments that have over 100 employees at the end of 2000. This sample consists of established firms rather than startups, which allows us to treat establishment location as determined prior to the Internet adoption decision. Approximately two-thirds of the U.S. workforce is employed in the type of establishments studied.

The sample contains considerable heterogeneity in the dimensions of interest. Establishments come from all over the United States, both major urban areas and isolated rural locations. Most of the organizations in the sample have some experience with basic IT technologies, such as personal computers (PCs), but a much smaller fraction have extensive experience with advanced IT projects. In addition, 45,948 establishments come from one of 7,035 multi-establishment organizations. This allows us to examine the potential for movement of resources between establishments in the same organization.

We analyze adoption of Internet technology involving communications internal to the establishment, which we label within-establishment Internet technology or WEI. Although the installation and maintenance costs of WEI vary on the basis of being in urban or isolated locations, its average benefits do not. We show that large establishments from firms in major cities will be most likely to adopt WEI, while small single-establishment companies in isolated locations will be least likely. We then disentangle the contribution coming from location and organizational resources by distinguishing between two sources of what we call capabilities, namely establishment capabilities located within the establishment and organizational capabilities located outside the specific establishment but inside the organization. We demonstrate that increases in establishment capabilities make a larger marginal contribution to technology adoption outside a major urban area than inside one: Establishments with high capabilities (one standard deviation above the mean) in remote locations have higher adoption rates than establishments with low capabilities in a dense location. We also demonstrate that increases in

more than one location, more than one establishment in a single area, or both. 
organizational capabilities make a larger marginal contribution to technology adoption outside a major urban area than inside one. These effects, however, are typically too small to make up for a poor location. These findings are robust to a wide variety of specifications and endogeneity controls and to alternative models and technologies.

Overall, our results show that the marginal effect of internal capabilities on adoption is lower in cities than in other areas. Firms act as if internal resources can substitute for the advantages of agglomeration. Through rendering the broad question in a concrete setting, our study improves understanding of why some firms were better able to take advantage of technical change both in this specific instance and more generally.

\section{Hypotheses}

As has been noted in many contemporary accounts, the rapid diffusion of the Internet took most commercial establishments by surprise. We consider a simple model of technology adoption at an establishment that assumes that new technology becomes available unexpectedly. The only decision for establishments is whether (and when) to adopt. Establishment $i$ will adopt by time $t$ if and only if

$$
\text { (1) } \quad N B\left(x_{i}, m e_{i}, e c_{i}, o c_{i}, z_{i}, t\right) \equiv B\left(x_{i}, m e_{i}, z_{i}, t\right)-C\left(x_{i}, m e_{i}, e c_{i}, o c_{i}, z_{i}, t\right)>0 \text {, }
$$

where $N B$ is the net benefit of adoption, $B$ is the gross benefit of adoption, and $C$ is the cost of adoption.

Our data come from one cross-section. Since adoption of the Internet is rarely reversed, we are comfortable suppressing the time dimension in our model. Under the standard "probit model" of diffusion (e.g., David 1969; Karshenas and Stoneman 1993), adoption costs decline over time for all potential adopters. As in this standard model, we interpret the difference between adoption and non-adoption as the threshold between those with high and low valuations from WEI adoption.

We let $x_{i}$ describe local geographic conditions, such as population size and density. The variables $m e_{i}, e c_{i}$, and $o c_{i}$, denote firm characteristics: $m e_{i}$ denotes whether the establishment is from a multiestablishment firm, $e c_{i}$ describes the establishment's internal capabilities, and $o c_{i}$ describes the presence of organizational capabilities (at other establishments within the same firm—by definition, $m e_{i}=1$ for 
establishments with $o c_{i}>0$ ). The variables $z_{i}$ describes industry and establishment characteristics. ${ }^{3}$

The WEI technologies involve communications internal to the establishment but not outside of the establishment. As was noted in Forman, Goldfarb, and Greenstein (2005), we expect cross-sectional variation in the gross benefits of WEI adoption to be minimal, but we do expect the costs of installation and maintenance to vary with locations. Thus, focusing on WEI allows us to assume a simpler model— $B\left(x_{i}, m e_{i}, z_{i}, t\right) \approx B+u_{i}$-where $B$ is a constant and $u$ is unobserved establishment-specific error. ${ }^{4}$ If $u$ is distributed as a normal i.i.d., then the probability of adopting is a function of how $x_{i}, m e_{i}, e c_{i}, o c_{i}$, and $z_{i}$ shape costs.

\subsection{Factors Shaping Adoption}

Figure 1 depicts the different mechanisms through which $x_{i}, e c_{i}$, and $o c_{i}$, influence the costs of adopting Internet technology at an establishment. Our main question is, What is the marginal contribution of each of those mechanisms? In this section, we develop hypotheses that frame our estimation strategy.

The variable $x_{i}$ captures differences in local supply conditions that arise as a result of changes in population size and density. Large cities may have thicker labor markets for complementary services or for specialized skills such as programming in new computer languages. Thicker markets lower the price of obtaining workers to perform development activities in-house or of obtaining IT services such as contract programming. Increases in location size also may increase the presence of non-market mediated knowledge spillovers that reduce adoption costs (e.g., Goolsbee and Klenow 2002). Such locations may also have greater availability of complementary information technology infrastructure, such as broadband

\footnotetext{
${ }^{3}$ We include the multi-establishment firm dummy and the number of employees (in $x_{i}$ ) to control for the well-known result that benefits to adoption are increasing in firm and establishment size. While we do not focus on how local competition influences the net benefits of adoption, we later present robustness checks that control for the extent of local competition.

${ }^{4}$ If we had examined a technology where the (gross) benefits decrease as city size increases-due, for example, to the ability of Internet technology to reduce the disadvantages associated with isolation $\left(d B / d x_{i}<0\right)$ - then we would not be able to identify the cost-reducing role of external resources because, as econometricians, we observe $d N B / d x_{i}$ $<0$, not $d C / d x_{i}$. In Forman, Goldfarb, and Greenstein (2005), we conclude that Internet technologies used for communication across business establishments displayed geographic patterns consistent with the "global village
} 
services. Increases in each of these factors may decrease the costs of adopting complex Internet technologies in cities, other things being equal. ${ }^{5}$

In Forman, Goldfarb, and Greenstein (2005), we conclude that the geographic variation in WEI adoption was consistent with the "urban leadership hypothesis," that is, adoption costs decrease as population size and density increase (i.e., $d C / d x_{i}<0$, where $x_{i}$ is density). We expect the same again. Hypothesis 1: Adoption of WEI will be increasing as location size and density increase.

Internal firm resources that arise as a result of prior investments in other IT projects may also lower adoption costs. We first discuss the role of $o c_{i}$ that arise from prior IT projects at other establishments and which are easier to identify in our data, and then discuss the role of $e c_{i}{ }^{6}$ The variable $o c_{i}$ captures how other IT projects at other establishments in the same organization affect the net benefits of Internet adoption, primarily by reducing the costs of operation and installation. These organizational capabilities are resources and investments that might be redeployed in other locations. That is, resources and other investments in the organization are already employed in some IT task, and the new technical opportunity leads them to be redeployed for use in advanced Internet applications. In the course of developing IT projects, organizations may develop shared human and physical capital that reduces the costs of developing Internet applications internally. These features will be important if there are significant fixed costs to develop this capital. Prior IT projects will also reduce development costs if programmers are able to transfer lessons learned from one project to another, which leads to economies of scale and scope. ${ }^{7}$ The benefits of these prior investments are organizational capabilities, but it is an open

hypothesis," $d B / d x_{i}<0$. Hence, these are the technologies we cannot examine with the framework used here. 5 This is consistent with prior theory work arguing that firms locate administrative and support functions strategically. Duranton and Puga (2002) argue that a firm may find it advantageous to locate administrative and support services in large areas because of better availability and a larger variety of complementary services. In addition, external services may require repeated face-to-face interactions (Kolko 1999). There is some evidence that locating such services in large metropolitan areas may improve firm productivity (Davis and Henderson 2002).

${ }^{6}$ Formal identification conditions are discussed in Section 3.3.

${ }^{7}$ For example, software developers may be able to share common tools for design, development, and testing (Banker and Slaughter 1997), or they may be able to reuse code (Barnes and Bollinger 1991). Software development may also have learning economies (Attewell 1992) that through experience reduce the unit costs of new IT projects. 
question of whether organizational capabilities move effectively across establishments within the same firm. If so, then adoption costs decrease $\left(d C / d o c_{i}<0\right)$ and our next hypothesis holds.

Hypothesis 2a: Firms with greater organizational capabilities will be more likely to adopt WEI technology at any one of their establishments than firms with lesser organizational capabilities.

The variable $e c_{i}$ measures capabilities at the same establishment. Establishment capabilities affect costs of adoption in ways similar to $o c_{i}$ : Shared human and physical capital, economies of scale and scope, learning economies, and knowledge spillovers might reduce adoption costs. Once again, it is an open question how establishment capabilities will affect adoption costs, if at all. Consequently, our next hypothesis concerns establishment capabilities and adoption costs $\left(d C / \operatorname{dec}_{i}<0\right)$. Hypothesis 2b: Greater establishment capabilities will increase adoption of WEI technology.

\subsection{Substitution}

Can prior experience with other IT projects at the same or at other establishments overcome the cost disadvantages of being outside a major urban area? ${ }^{8}$ Evidence on this question is scarce or has ambiguous interpretations, especially with regards to the performance of innovative activity. ${ }^{9}$ Our next two hypotheses posit that capabilities substitute for the advantage of being located in a major urban area, that is, the cost advantages of location in a city decline in the presence of organizational capabilities $\left(d^{2} C / d x_{i} d o c_{i}<0\right)$ and establishment capabilities $\left(d^{2} C / d x_{i} d e c_{i}<0\right) .{ }^{10}$ For example, shared human capital arising from other projects at the same establishment may decrease the benefit of increases in the local

The IT projects may also be subject to knowledge spillovers that reduce development costs. Much prior research in the costs of innovative activity has also long presumed experience with prior related projects can lower the costs of innovation (Cohen and Levinthal 1990). Internal capabilities may also help customize a general purpose technology, such as the Internet, to the idiosyncratic needs of the establishment (Forman, Goldfarb, and Greenstein, 2002).

${ }^{8}$ Vernon (1963) first articulated this idea in a case study of the New York City area. He argues that agglomeration economies are especially important for small (start-up) firms that lack scale economies in their own organizations. ${ }^{9}$ One exception is Kelley and Helper's (1999) study, which shows that urbanization and localization increase the speed of computer numerical control adoption among a sample of manufacturers. Their research, though, is a case study based on a small sample of industries. Most evidence in other industries suggests a relationship between agglomeration and factors associated with internal capabilities (Holmes 1999, Holmes and Stevens 2002; Henderson 2003). For example, manufacturing firms in isolated locations tend to use more self-supplied intermediate inputs.

${ }^{10}$ This discussion presumes that we can both measure and identify establishment location and capabilities distinctly 
supply of third-party services. Moreover, when IT labor forces are mobile, shared human capital at other establishments decrease the value of consultants and thicker labor markets in large cities. Further, as noted above, prior work on other IT projects may create learning economies and spillovers that decrease the costs of adapting general purpose IT to organizational needs, reducing the importance of external consultants and local spillovers. These alternative mechanisms lead to the same empirical prediction: the marginal contribution of internal capabilities is higher outside cities than inside.

Access to broadband is available for most of the medium and large establishments we observe, but, as with other local services, the competitiveness of local broadband markets varies widely between urban and rural areas. Our hypothesis presumes that the marginal WEI investment will be decided based on human capital issues instead of infrastructure issues. However, we note the possibility that broadband may be unavailable in rural areas, in which case internal capabilities will not be a substitute for a lack of local infrastructure. We treat this possibility as an empirical question. ${ }^{11}$

Hypothesis 3a: The sensitivity of WEI adoption to increases in location size will be declining as the internal organizational capabilities found in other establishments within the same firm increase.

Hypothesis 3b: The sensitivity of WEI adoption to increases in location size will be declining as the internal establishment capabilities increase.

In our final hypothesis we expect increases in IT capabilities in the organization (establishment) will decrease the rate at which the establishment (organization) capabilities influence costs $\left(d^{2} C / d o c_{i} d e c_{i}<0\right)$ : that is, $o c_{i}$ and $e c_{i}$ are substitutes. ${ }^{12}$ Establishment and organization capabilities will substitute when internal IT labor forces can be deployed on projects throughout the organization, or when

from other factors. This challenge frames several of the econometric issues we discuss subsequently.

${ }^{11}$ If differences in broadband availability do constrain the value of an establishment's Internet investments in enough cases, then internal capabilities and agglomeration would be complements on average, leading to a coefficient estimate that rejects hypotheses $3 \mathrm{a}$ and $3 \mathrm{~b}$.

${ }^{12}$ If establishments specialize in differing "types" of capabilities, then establishment and organizational capabilities may be complements. Again, we treat this alternative hypothesis as an empirical question. 
learning economies and knowledge can be transmitted across IT projects at different establishments. ${ }^{13}$

Hypothesis 4: Establishment capability and organizational capability are substitutes.

\section{Data and Method}

The data used in this study come from the Harte Hanks Market Intelligence Computer Intelligence Technology database (hereafter CI database) ${ }^{14}$ This database contains establishment- and firm-level data on characteristics such as number of employees and number of programmers and use of Internet applications and other networking services. Harte Hanks collects this information to resell as a tool for the marketing divisions of technology companies. Interview teams survey establishments throughout the calendar year; our sample contains the most current information as of December 2000.

Harte Hanks tracks over 300,000 establishments in the United States. Because we focus on commercial Internet use, we exclude government, military, and nonprofit establishments (mostly in higher education). Our sample from the CI database contains all commercial establishments with over 100 employees - in total 115,671 establishments. Harte Hanks provides one observation per establishment. We use the 86,879 clean observations with complete data generated between June 1998 and December 2000. ${ }^{15}$ Harte Hanks tracks whether an establishment is affiliated with a larger organization. In total, there are 47,966 distinct organizations, and 7,035 of these have more than one establishment. We adopt a strategy of utilizing as many observations as possible for establishments in thinly populated areas. This necessitates routine adjustments for the timing and type of the survey given by Harte Hanks.

\subsection{Endogenous Variables}

Our analysis focuses on advanced Internet technology, or WEI, that either changes existing internal

\footnotetext{
${ }^{13}$ Some prior research using patent citations has provided evidence of intra-firm knowledge spillovers in other innovation settings (e.g. Frost 2001, Furman, Kyle, Cockburn and Henderson, 2005).

${ }^{14}$ This section provides an overview. For more detail, see Forman, Goldfarb, and Greenstein (2002).

${ }^{15} \mathrm{We}$ dropped establishments that did not indicate when they were surveyed and establishments that were not surveyed on information technology. There is a small bias in the dropped observations toward locations where WEI adoption is high. The weighting scheme controls for any location and industry bias in the sample.
} 
operations or implements new services. We look for indications that an establishment has made investments that involved frontier technologies or substantial co-invention. The threshold for defining substantial is necessarily arbitrary within a range. ${ }^{16}$ It usually arises as part of other intermediate goods, such as software, computing, or networking equipment. Investment in WEI involves the use of Internet protocols in the input and output of data to and from business applications software. Examples include (1) intranet applications that enable Web access to information stored in business applications software, such as inventory or accounting data and (2) applications that have functionality involving integration with back-end databases (e.g., Web access to a data warehouse). ${ }^{17}$

Firms adopting complex applications such as WEI may do so at only a subset of establishments. As we subsequently discuss in further detail, such adoption may cloud the relationship between geography, internal capabilities, and technology adoption in our establishment-level regressions.

Hence, as a robustness check, we also examine the determinants of two additional measures of adoption behavior. One such measure describes whether the IT personnel at the establishment are using languages that are commonly employed in the building of Internet applications. This variable is equal to one when the establishment indicates the use of any of the following: XML, Visual Basic Script, Perl, Java, CGI, and Active-X. The second variable describes when an establishment has made necessary hardware investments to host Internet applications, and it is equal to one when the establishment has installed a PC server. Both of the measures represent investment in intermediate inputs that are used in the building and hosting of Internet applications and may be duplicated at multiple establishments.

\footnotetext{
${ }^{16}$ We tested a number of slightly different definitions and did not find any significant changes to our findings. ${ }^{17}$ To be specific, an establishment is counted as adopting WEI if it adopts one of the following: (1) business application software that involve intensive use of database management systems, such as accounting, sales and marketing, payroll, ERP and MRP, inventory, order processing, and data warehousing; (2) science and research applications used for financial analysis and modeling, CAD/CAM/CAE, data analysis, and engineering; or (3) office applications, such as personnel management, project management, and groupware. See Forman, Goldfarb, and Greenstein (2005) for more details.
} 


\subsection{Exogenous Variables}

In Table 1, we provide descriptive statistics. Our measure of location size is a dummy variable that equals one when the establishment is located in a metropolitan statistical area (MSA) with a population over 500,000, which we term sizeable MSA. This is the simplest way to represent differences between large cities and small cities and rural locations. In our earlier research, we considered a wide variety of different specifications for the effect of increasing density, and these specifications largely did not affect the results. Here, we employ a dummy for "city" to keep the results stark and easy to interpret. We also demonstrate that variants on this definition do not affect our qualitative inferences.

We measure mobile capabilities that can be deployed to build new Internet applications. Our first measure of capabilities is based on the number of programmers. For establishment capabilities, we measure the number of programmers located within the establishment. For organizational capabilities, we examine only the multi-establishment firms within our sample. We compute the total number of programmers from other establishments within the same firm. ${ }^{18}$ These measures quantify the total number of programmers instead of the total quality of programmers or the total cost of programmers. If major urban areas have different programmer quality or costs than other areas, this may have (ambiguous) implications on the productivity implications of our results for establishment capabilities. ${ }^{19}$

Our second measure of establishment capabilities utilizes principal components factor analysis on three variables—employment, programmers, and a measure of non-Internet software use-to compute a composite variable. This variable provides a more complete description of internal capabilities. The variable on software use is a dummy that is equal to one when the establishment uses internal application

\footnotetext{
${ }^{18}$ In our database, the programmers variable is constructed using the following cells: 1-4, 5-9, 10-24, 25-49, 50-99, 100-249, 250-499, and 500 or more. To convert this measure into a continuous variable, we take the midpoint of each interval and use 500 as the value for the right-censored observations. In our sample, less than $1 \%(85)$ of the establishments have a right-censored value for programmers. Qualitative results do not change if a dummy for 500 or more is included (results available upon request.)

${ }^{19}$ If urban areas have thicker labor markets for higher quality programmers at the same wage rates as rural areas then that would bias our estimates away from hypothesis $3 \mathrm{a}$ and $3 \mathrm{~b}$. If urban areas have higher wage rates for higher or same quality programmers, then the bias in our estimate is ambiguous.
} 
development software or when it has familiarity with current object-oriented programming languages such as $\mathrm{C}$ or $\mathrm{C}++.{ }^{20}$ Only one factor has an eigenvalue above one and was therefore the only one retained. This factor explains $50 \%$ of the variance. We label this factor the establishment capability factor.

For organizational capability, we again conducted principal components factor analysis on five variables: (1) total employment in the organization outside the establishment, (2) number of programmers in the organization outside the establishment, (3) a dummy for whether at least one other establishment in the organization used development software, (4) a dummy for whether at least five other establishments in the organization used development software, and (5) a dummy for whether at least ten other establishments in the organization used development software. Again only one factor has an eigenvalue above one. It explains $59 \%$ of the variance. We label this factor the organizational capability factor. ${ }^{21}$

Table 1 shows that there are few systematic differences in the distributions of either organizational capability measure. For the establishment capability measures, both the means and the standard deviations are slightly higher in cities. The differences are small enough not to affect our interpretation of the marginal effects across major cities and other areas.

Our regressions also include controls for establishment employment, controls for whether the establishment is part of a multi-establishment firm, three-digit NAICS dummies, and dummies for the month the survey was conducted. ${ }^{22}$ These variables control for many other unmeasured determinants of demand and supply.

\subsection{Statistical Method}

We estimate a probit model of adoption for the WEI technologies previously described. Our endogenous

\footnotetext{
${ }^{20}$ We experimented with a variety of alternative measures of software use, including additional measures of development applications as well as measures of complex client/server applications such as enterprise resource planning. These alternative measures gave qualitatively similar results.

${ }^{21}$ We also experimented with adding quadratic and other higher-order terms for establishment and organization capabilities. These terms had no effect on adoption.

${ }^{22}$ Establishments were interviewed over a two-year period. Those interviewed toward the end of the period are more likely to have adopted. Therefore, we control for the month surveyed.
} 
variable is $y_{j}$, the value to establishment $j$ of WEI adoption. The variable $y_{j}$ is latent. We observe only discrete choices, namely, whether or not the establishment chooses to adopt a technology. In either case, the observed decision takes on a value of either one or zero.

In our base specification we assume the value to adopting WEI technology is

$$
\text { (2) } y_{i}=\alpha x_{i}+\beta o c_{i}+\gamma e c_{i}+\delta o c_{i} x_{i}+\phi e c_{i} x_{i}+\lambda o c_{i} e c_{i}+\theta_{1} m e_{i}+\theta_{2} z_{i}+\varepsilon_{i}
$$

where $\alpha$ captures the influence of location on adoption, $\beta$ captures the influence of organizational capability on adoption, $\gamma$ captures the influence of establishment capability on adoption, $\delta$ captures whether organizational capability and location are substitutes, $\phi$ captures whether establishment capability and location are substitutes, $\lambda$ captures whether organizational capabilities and establishment capabilities are substitutes, $\theta_{1}$ controls for whether the establishment is part of a multi-establishment firm and $\theta_{2}$ captures the influence of a vector of controls including three-digit NAICS industries, employment, and time of survey. The role for capabilities and location is therefore identified from the variation between establishments within the same industry. We weight models by the actual geographic distribution of establishments for industry and size, according to Census County Business Patterns data. If our data under samples a given two-digit NAICS at a location relative to the Census then each observation in that NAICS-location is given more importance (for details, see Forman, Goldfarb, and Greenstein 2002).

This study focuses on the coefficient estimates for $\alpha, \beta, \gamma, \delta, \phi$, and $\lambda$, which represent the influence of internal capabilities in reducing (or enhancing) the importance of agglomeration on WEI adoption at the organization and establishment level. The estimation of $\theta_{1}$ and $\theta_{2}$ is needed to control for other factors that may affect WEI adoption. With these controls, a positive sign on $\alpha$ supports Hypothesis 1, a positive sign on $\beta$ supports Hypothesis $2 \mathrm{a}$, a positive sign on $\gamma$ supports Hypothesis $2 \mathrm{~b}$, a negative sign on $\delta$ combined with a positive sign on $\beta+\delta$ supports Hypothesis 3a, a negative sign on $\phi$ combined with a positive sign on $\gamma+\phi$ supports Hypothesis $3 \mathrm{~b}$, and a negative sign on $\lambda$ supports Hypothesis 4 .

Our identification strategy relies on four core assumptions. First, we assume that the location of an establishment is predetermined. Hence, it is econometrically exogenous to the decision to adopt WEI 
technology. This assumption is supported by the unexpectedly rapid diffusion of the Internet. Also, the establishments in our sample are large and from firms with long histories. They did not suddenly relocate when the Internet became available. Said succinctly, we assume that the average unobserved benefits of adopting WEI are independent of where establishments are located, be they in urban or rural areas.

Second, we assume that our estimates are not influenced by firm-level simultaneity bias. Our base econometric specification assumes i.i.d. errors. In other words, we assume the error in measuring the adoption decision of one establishment is independent of the error in every other establishment's adoption decision, including other establishments in the same firm. We recognize that this assumption is questionable for multi-establishment firms in which a central executive decision maker (e.g., Chief Information Officer) possibly coordinates the choice of whether to adopt for each establishment under his domain and allocates mobile internal capabilities across establishments within the firm. In particular, if IT investment decisions are centralized and these firms have greater capabilities, then the coefficient estimates for capabilities for multi-establishment firms will be biased. To look for biases, we estimate the coefficients both with all the data and with a subsample of establishments with autonomy to make their own decisions. Furthermore, while we present results without clustering of standard errors, all of our significance results are robust to clustering the standard errors by firm.

Third, our econometric model assumes that capabilities are exogenous to the decision to adopt the technology. In support of this assumption we note that many of the establishments in our sample maintain large Information Systems groups that support many internal IT services, so that the WEI technologies will be only one of many projects. Yet, we also recognize that marginal changes in our measures of capabilities could make them statistically endogenous. We believe that endogeneity most likely upwardly biases the coefficients on capabilities, that is, in the event that capabilities and IT capital decisions are codetermined. If this bias arises, it biases our establishment capability estimates in favor of Hypothesis $2 \mathrm{~b}$. It is less likely to bias our organizational capability estimates.

We take several actions to control for this third form of endogeneity. As was previously noted, we re-estimate our regressions over a subsample in which the establishments have autonomy to make IT 
investment decisions. If the bias is large, then this subsample should alter the estimate on organizational capabilities, but not establishment capabilities. In other words, if the bias is large, the result is more likely to hold for Hypothesis $2 \mathrm{~b}$ in this subsample, but it is not more likely for Hypothesis $2 \mathrm{a}$. Next, we estimate capabilities in a variety of ways while looking for robustness. We also present results of instrumental variables regressions that use capabilities of other establishments and organizations in the same industry as instruments for establishment and organizational capability. We also instrument for endogeneity of the location-capability interaction variable with capability of other establishments in other industries in the same location. While we do present results of instrumental variables regressions that control for potential endogeneity between establishment and organization capability levels, we have no reason to believe the endogeneity affects the interaction between capabilities and location. Our results support this belief because we find no qualitative differences in the core results of a number of different specifications.

Fourth and finally, our statistical approach relies on the accumulated weight of many different tests, not any specific coefficient estimate. Any specific coefficient estimate is vulnerable to concerns that unmeasured demand correlates with our measures of costs, especially those in Hypothesis $2 \mathrm{~b}$, as was noted above. Nevertheless, we gain confidence in our interpretation from estimating the sensitivity of the statistical inference to a variety of (1) different estimation corrections, (2) different implementations for the endogenous and exogenous variables, and (3) different samples.

\section{Results}

\subsection{How Does Location Affect the Contribution Of Internal Capabilities?}

In this section, we first show the impact of changes in location size and internal capabilities on IT investment. We then examine the interaction between the roles of internal capabilities and of cities on technology adoption. The results in Columns (1) through (4) of Table 2 show the coefficients of the main results; those in Columns (5) through (8) show the marginal effects.

We first show that urban leadership holds for WEI, supporting Hypothesis 1. Specifically, an increase in location size has a significantly positive effect on the adoption of WEI technology. The results 
in Columns (5) and (6) show that establishments that are located in sizeable MSAs are 1.3 percentage points to 1.8 percentage points more likely to adopt WEI. Agglomeration in economic activity increases the likelihood of adoption, other things being equal.

Increases in capability significantly increase adoption, which supports Hypotheses $2 \mathrm{a}$ and $2 \mathrm{~b}$. Increases in establishment capabilities have a significantly positive effect (at the $1 \%$ level) on the adoption of WEI in all specifications. A one-standard-deviation increase in the log of the number of programmers at the establishment increases adoption by 3.6 percentage points. ${ }^{23}$ This is a significant increase when compared to the adoption rate of $11.9 \%$. A one-standard-deviation (equivalent to one unit by construction) increase in our composite establishment capability factor has a similar effect, namely, increasing the adoption of WEI by 3.0 percentage points. Internal establishment capabilities significantly reduce the costs of adoption.

Increases in organizational capabilities have a similar, but smaller, impact on WEI adoption. A one-standard-deviation increase in the log of the number of programmers increases the likelihood of adopting WEI by 0.45 percentage points, which is statistically significant at the $1 \%$ level. Increasing the composite organizational capability factor by one standard deviation increases the likelihood of adoption by 0.6 percentage points. Although these effects are smaller than those for establishment capabilities, they are still large when compared to the adoption rates for WEI.

We next examine the extent to which internal capabilities can substitute for the benefits of agglomeration. The results in Columns (3), (4), (7) and (8) of Table 2 present the main results of our paper. Later, in Tables 4 through 6, we show the results of a number of robustness checks. The key effects of agglomeration and internal capabilities are similar to those in Columns (5) and (6). The key effects are all in the expected direction and significant at the $1 \%$ level.

There is considerable evidence that internal capabilities substitute for the benefits of

\footnotetext{
${ }^{23}$ These quantities are computed by multiplying the marginal effect by the change in the variable.
} 
agglomeration, supporting Hypotheses $3 \mathrm{a}$ and $3 \mathrm{~b}$. In Table 2, the interactions between internal capabilities and $x_{i}$ are all in the expected direction and significant at the $1 \%$ level. The results in Column (7) show that establishments outside cities benefit 0.9 percentage points more than establishments in cities from a onestandard-deviation increase in the log of organizational programmers. Similarly, establishments outside cities benefit 1.1 percentage points more from a one-standard-deviation increase in the log of establishment programmers. Interestingly, while establishment programmers have a much stronger effect on the likelihood of adoption than organizational programmers (marginal effects of 3.6 percentage points versus 0.2 percentage points), the extent of substitution between cities and establishment capabilities is almost equal to that of cities and organizational capabilities. This suggests that while only a fraction of organizational capabilities are mobile, they perform similar activities to establishment capabilities and are able to substitute similarly for cities. ${ }^{24}$

To put this in perspective, at mean values for organizational programmers, establishments in cities are 3.6 percentage points more likely to adopt than establishments in other areas. At the $90^{\text {th }}$ percentile, the difference is just 1.4 percentage points. Similarly, at mean values for establishment programmers, establishments in cities are 4.3 percentage points more likely to adopt WEI than establishments in other areas; however, establishments in cities with values for establishment programmers that are at the $90^{\text {th }}$ percentile are only 1.4 percentage points more likely to adopt than those with equivalent capabilities in other areas. Similar results hold for our composite capability variables. Thus, Hypotheses $3 \mathrm{a}$ and $3 \mathrm{~b}$ are strongly supported.

Figure 2 presents another view of the main results. It presents the predicted probabilities of adopting WEI using the results in Column (3) of Table 2 under different combinations of location size and internal capabilities. In this figure, we use of the log of programmers as our measure of internal capabilities; results using our composite measure of capabilities are qualitatively similar. We now discuss

\footnotetext{
${ }^{24}$ These results are also robust to allowing organizational capabilities in the same location (MSA or state) or in the
} 
Figure 2a, which presents the results for organizational capabilities, and we compare the results briefly to the results for establishment capabilities in Figure 2b, which are qualitatively similar: Figure $2 a$ shows the positive impact of agglomeration on adoption (Hypothesis 1). When the firm has no internal organization capabilities, location in a sizeable MSA increases the probabilities of adoption considerably, from $11.6 \%$ to $16.1 \% .^{25}$ This 4.5 percentage point increase is the difference at the intercept. Moreover, Figure 2a provides support for Hypothesis 2a: The upward sloping lines show that the probability of WEI adoption increases as organization capabilities increase, whether or not the establishment is in a sizeable MSA.

Figures 2a also demonstrates how the prediction of Hypothesis 3a shapes adoption behavior: The curve depicting establishments in sizeable MSAs is flatter than that for other establishments. The marginal impact of increasing organizational capabilities is lower for organizations in sizeable MSAs: Changing — from low $\left(o c_{i}=0\right)$ to average $\left(o c_{i}=1.738\right)$ capabilities increases the probability of WEI by 1.5 percentage points for establishments in low-density areas, and increases the probability by 0.5 percentage points for establishments in an urban location. Organizational capabilities, however, are unable to completely substitute for the benefits of an urban location. Even for very capable organizations that are one full standard deviation above the mean $\left(o c_{i}=4.028\right)$, adoption rates are 2.3 percentage points higher in sizeable MSAs than in rural areas. ${ }^{26}$ In summary, we find no evidence that organizational capabilities and agglomeration are complements.

These results illustrate the importance of establishment capabilities, organizational capabilities, and external capabilities in reducing the costs of adoption. Although it is difficult to compare them because of differing metrics, the slopes of the organizational capabilities lines in Figure 2a are not nearly as steep as the slopes of the establishment capabilities lines in Figure 2b. For establishments located

same industry (three- or six-digit NAICS) to have a separate effect on adoption costs.

${ }^{25}$ Simulations assume establishment capabilities are equal to zero.

${ }^{26}$ To ensure the results are not driven by functional form, we estimated a quadratic specification of capabilities. The coefficients on establishment capabilities squared, organizational capabilities squared, and their interactions with the city dummies are both statistically and economically insignificant. Results are available upon request. 
outside of cities, an increase in establishment capabilities from zero to their mean level $\left(e c_{i}=0.510\right)$ increases the likelihood of adoption by 4.1 percentage points, while an increase in establishment capabilities from zero to their mean level $\left(o c_{i}=4.028\right)$ increases the likelihood of adoption by 1.6 percentage points. These results reflect the coefficient estimates on establishment and organizational capabilities in the first two rows of Table 2.

Moreover, these figures also are suggestive about the relative importance of internal versus local external capabilities in lowering adoption costs. For example, an establishment with high organizational capabilities (one standard deviation above the mean), which is located in a low-density location has a lower adoption rate (15.0\%) than a similar establishment with zero organizational capabilities, which is located in a high-density location (16.1\%). Yet, an establishment with high establishment capabilities in a low-density location has a higher adoption rate $(24.6 \%)$ than a similar establishment with mean values for establishment capability and a high-density location (19.5\%).

Overall, these results suggest that internal capabilities are substitutes for agglomeration when adopting complex technologies. Yet, they also suggest that internal establishment capabilities are more effective at lowering adoption costs than are organizational capabilities.

\subsection{Substitutability of Organizational Capability and Establishment Capability}

In Table 3, we present evidence that establishment and organizational capabilities are substitutes (Hypothesis 4). No matter how we measure capabilities, the interaction between organizational and establishment capabilities is negative and significant at the one-percent level. ${ }^{27}$ The results in Column (2) show that at mean values for the log of establishment programmers, an increase in the log of organization programmers by one standard deviation will decrease the marginal effect of establishment capabilities by 0.42 percentage points. This magnitude is of moderate size when compared to the effect of establishment

\footnotetext{
${ }^{27}$ Capability is potentially endogenous if establishments in weak organizations hire more programmers to implement a planned adoption. Nevertheless, the negative correlation on the interaction term still suggests substitutability between establishment and organizational capabilities irrespective of the direction of causality.
} 
capabilities on adoption. By comparison, an increase in the log of establishment programmers from 0 to its mean value will increase the likelihood of adoption by 2.69 percentage points when organizational capabilities are equal to zero, that is, when the establishments have no organizational capabilities.

The results for our composite measure are similar: Assuming a value for our composite establishment factor of one, a one standard deviation increase in organizational capabilities will decrease the marginal effect of establishment capabilities by 0.84 percentage points. By comparison, an increase in the establishment capability composite variable from 0 to 1 will increase the probability of adoption by 5.66 percentage points. Overall, these results suggest that there exists significant substitution between establishment and organizational capabilities for WEI adoption.

\subsection{Robustness Checks}

In Tables 4 through 6, we show the results of a number of robustness checks. In Table 4, we explore the exogeneity assumptions relating to location and capability. In Table 5, we explore definitions by city size and technology adoption. In Table 6, we examine whether our results are driven by industry competition.

Columns (1) and (2) of Table 4 show data only for establishments in multi-establishment firms that reported that their IT investment decisions are made locally at the establishment. Our baseline specification implicitly assumes that the error terms of establishment adoption decisions are independently distributed. This assumption is particularly likely to hold for this subset of establishments. Although this reduces our sample size considerably, the qualitative results remain the same.

For the remainder of Table 4, we use instrumental variables techniques to examine the assumption of exogenous capabilities. In particular, instrumental variables probit regressions were used. Following Maddala (1983, p. 247-52), we used Amemiya Generalized Least Squares. ${ }^{28}$ We define five instruments. One, we instrument for a firm's establishment capabilities with the establishment capabilities of other establishments in other firms in the same two-digit NAICS industry in the other locations that the

\footnotetext{
${ }^{28}$ In the first stage, the endogenous variables are treated as a linear function of the instruments and the exogenous
} 
firm has an establishment. Two, similarly, we instrument for a firm's organizational capabilities with the organizational capabilities of other establishments in other firms in the same two-digit NAICS industry in other locations where the firm has an establishment. These instruments should be correlated with the capabilities of an establishment but not with the propensity of the establishment to adopt, conditional on its industry. Three and four, we use two instruments for the interaction of establishment capability and city. First, we interact the previous instrument for establishment capabilities (i.e., instrument 1) with a city dummy. Second, we use establishment capabilities at other establishments in other industries in the same location. These capabilities will be affected by the same local supply conditions but will not be directly correlated with adoption. For our fifth instrument we construct the interaction of organizational capabilities and cities with the interaction of the previous instrument for establishment capabilities (i.e., instrument 1) by using other establishments in the same location with a city dummy. ${ }^{29}$ We therefore have five main instruments for four potentially endogenous variables.

As was noted, we are concerned that establishment and organizational capabilities may be correlated with adoption. In Columns (3) and (4), we use instruments for the establishment and organizational capabilities variables. They do not instrument for the interactions of these variables with location. While significance on the interaction term for establishment capability is lost when capability is defined by programmers, all other significance remains and the signs do not change. The main results do not appear to be driven by the endogeneity of the capabilities variables. Nevertheless, it is also possible that establishments or organizations in particular locations are more capable. Therefore, to ensure robustness, in Columns (5) and (6), we use all five instruments for the four potentially endogenous variables, namely, establishment capability, organizational capability, and their interactions with being in a city. Establishment and organizational capability are still positively correlated with adoption, and while

variables. The second stage probit uses the predicted values for the endogenous variables from the first stage.

${ }^{29}$ We do not use the organizational capabilities equivalent to the second establishment capabilities instrument, because it is not clear how organizational capabilities of establishments in a city will be correlated. 
some significance disappears, the coefficient on the interaction of being in a city with either capability measure is negative. In summary, the results are robust to instrumental variables techniques.

In Table 5, we explore the robustness of the variable definitions. Columns (1) through (4) show that the results are robust to different definitions of what constitutes a city. In our base specification, we define a city as an MSA with a population of over 500,000. Columns (1) and (2) define a city as any MSA. Columns (3) and (4) define a city as a location with a population density greater than the sample median (610 people per square mile). We also ran regressions that use three kinds of MSA: small $(<500,000)$, medium (500,000-1 million), and large (over 1 million). The establishment capabilities interaction is largely monotonic in city size. The main divide for organizational capabilities is between MSAs and non-MSAs. ${ }^{30}$ In all cases, the qualitative results remain the same. ${ }^{31}$ Columns (5) through (8) of Table 5 check the interaction of location and capabilities on different technologies. The results for Internet development languages (columns (5) and (6)) and PC servers (columns (7) and (8)) are similar to the results for WEI.

We also examined whether our results were specific to any particular sector of the economy. The results in Appendix Table 1 show that the substitutability between internal and external factors holds across a number of industries and is not special to any particular sector of the economy.

Sizeable MSAs not only have greater external resources, but may also have stronger competition in industries that sell non-tradeable goods and services. Thus, our city dummy may also capture the effects of competition. To examine this hypothesis, the results in Table 6 show whether our results are robust to the inclusion of variables measuring competition. In Columns (1) and (2), we include the total number of other establishments in the establishment's same six-digit NAICS and county, and in Columns

\footnotetext{
${ }^{30}$ The coefficients on the interactions of establishment capabilities and city sizes are $-0.0357,-0.0796$, and -0.0989 for small, medium, and large MSAs respectively (non-MSA is the base). For organizational capabilities, the coefficients are $-0.0408,0-.0408$, and -0.0456 respectively. Full results are available from the authors on request. ${ }^{31}$ The inference also does not change with other city definitions, including MSAs with a population of over one million, a continuous population measure, and a continuous density measure. Results are available upon request.
} 
(3) and (4), we include the total employment in the same six-digit NAICS and county. We also interact these variables with establishment and organizational capabilities.

If our city dummy proxies for external resources beyond the effects of competition, our core results should remain qualitatively unchanged. They do. In particular, Columns (1) and (3) show that our results using establishment and organizational programmers remain significant at the $5 \%$ level, regardless of whether we include establishments or employment in the same industry-county. Columns (2) and (4) show that our results using establishment factors remain significant at the $1 \%$ level, while our results using organizational factors are significant only when we use employment measures of competition (at the $10 \%$ level). As a further robustness check, we also examined whether these results were robust to estimating these regressions using only establishments in service industries. Service sector establishments will be more likely to be influenced by competition with local establishments. Again, these results are

qualitatively the same. ${ }^{32}$ Overall, the proxies for competition have little impact on our core results.

\section{Discussion and Conclusions}

We show that the marginal contribution of internal capabilities to technology adoption is lower for establishments in urban locations than for establishments elsewhere. We also find a symmetric role for internal capabilities: Establishments that are in firms with a greater number of IT personnel adopt WEI technology more quickly, as did those with prior experience with related non-Internet applications. Overall, we conclude that establishments located in major urban areas behave as if they face fewer constraints and have lower costs of adopting WEI technology.

These findings suggest that the advantages of agglomeration will be most important for singleestablishment firms that have been unable to develop internal capabilities. The findings are consistent with researchers who have argued that agglomeration of firms with similar input demands can provide benefits through the provision of complementary third party services and knowledge transfers. These 
benefits will be most valuable among small firms and for firms in young or infant industries, where internal capabilities and business processes are still being developed.

Our findings are also consistent, albeit more speculatively, with researchers who have argued that as industries mature and average firm size increases, there is less need for the complementary resources and knowledge transfer found in cities. As a result, firms may relocate to shape their innovative activities (Furman, Kyle, Cockburn and Henderson, 2005), or economize on transportation costs or save on wages (Duranton and Puga 2001). Nevertheless, caution is warranted in following this line of reasoning. We have examined only one reason why firms would desire urban locations. When a technology diffuses (whether expected or not - in our case, not), the costs of adopting are lower in a city. Firms may agglomerate in the same location for a variety of related reasons: knowledge transfer, labor market pooling, knowledge spillovers, and transportation costs among them.

This study raises several questions for further research. First, our findings are consistent with the view that large firms with mobile organizational capabilities may be more likely to locate IT-intensive business processes in low-cost remote locations. Second, these findings further reinforce the theme of our earlier research - that location shapes decisions to develop new IT applications internally or decisions to use external resources, both market-mediated and not. Third, the results also suggest that the competitive advantage associated with investing in advanced IT depends partially on the preexisting locations of establishments. Fourth, our findings imply that since businesses in large urban areas have access to both internal and external sources of supply of IT capabilities they will have lower costs of adoption and use for frontier IT. Productivity should therefore be higher on average for the same dollar of IT capital. Finally, these themes have implications for ongoing research about outsourcing. It is a comparatively unexplored theme in outsourcing research whether the location of an establishment shapes the propensity of establishments to use market-mediated external channels for IT application development.

\footnotetext{
${ }^{32}$ For brevity, these results are not included in any tables. They are available from the authors upon request.
} 


\section{References}

Ástebro, Thomas. 2002. Noncapital Investment Costs and the Adoption of CAD and CNC in U.S. Metalworking Industries, Rand Journal of Economics 33(4): 672-88.

Attewell, Paul. 1992. Technology Diffusion and Organizational Learning: The Case of Business Computing, Organizational Science 3 (February): 1-19.

Banker, Rajiv and Sandra Slaughter. 1997. A Field Study of Scale Economies in Software Maintenance, Management Science 43(12): 1709-25.

Barnes, B.H. and T.B. Bollinger. 1991. Making Reuse Cost-Effective, IEEE Software 8(1): 13-24.

Cohen, Wesley M. and Daniel A. Levinthal. 1990. Absorptive Capacity: A New Perspective on Learning and Innovation, Administrative Science Quarterly 35: 128-52.

Columbo, Massimo and Rocco Masconi. 1995. Complementarity and Cumulative Learning Effects in the Early Diffusion of Multiple Technologies, Journal of Industrial Economics 43(1): 13-48.

David, Paul A. 1969. A Contribution to the Theory of Diffusion, Memorandum No. 71, Stanford Center for Research in Economic Growth, Stanford University.

Davis, James C. and J. Vernon Henderson. 2002. Headquarters' Location Decisions, Working Paper, Department of Economics, Brown University.

Duranton, G. and D. Puga. 2001. Nursery Cities: Urban Diversity, Process Innovation, and the Life Cycle of Products, American Economic Review 91(5): 1454-77.

and 2002. From Sectoral to Functional Specialization, NBER Working Paper \#9112, Cambridge, MA.

Forman, Chris, Avi Goldfarb, and Shane Greenstein. 2002. Digital Dispersion: An Industrial and Geographic Census of Commercial Internet Use, NBER Working Paper \#9287, Cambridge, MA.

— $\longrightarrow$, and 2005. How Did Location Affect Adoption of the Commercial Internet? Global Village vs. Urban Leadership, Journal of Urban Economics (forthcoming).

Frost, Tony. 2001. The Geographic Sources of Foreign Subsidiaries Innovations. Strategic Management Journal 22: 101-123.

Furman, Jeffrey L., Margaret K. Kyle, Iain Cockburn, and Rebecca Henderson. 2005. Public \& Private Spillovers, Location, and the Productivity of Pharmaceutical Research. Working Paper, School of Management, Boston University.

Goolsbee, Austan and Peter Klenow. 2002. Evidence on Learning and Network Externalities in the Diffusion of Home Computers, Journal of Law and Economics 45(2): 317- 44.

Henderson, J. Vernon. 2003. Marshall's Scale Economies. Journal of Urban Economics 53(1): 1-28..

Holmes, Thomas J., 1999, Localization of Industry and Vertical Disintegration, Review of Economics and Statistics, Vol. 81, No. 2, May 1999, 314-25.

Holmes, Thomas J. and John J. Stevens. 2002. Geographic Concentration and Establishment Scale, Review of Economics and Statistics 84(4): 682-90.

Karshenas, Massoud and Paul Stoneman. 1993. Rank, Stock, Order, and Epidemic Effects in the Diffusion of New Process Technologies: An Empirical Model Rand Journal of Economics 24(4): 503-28.

Kelley, Maryellen and Susan Helper. 1999. Firm Size and Capabilities, Regional Agglomeration, and the Adoption of New Technology, Economics of Innovation and New Technology 8: 79-103.

Kolko, Jed. 1999. Can I Get Some Service Here? Information Technology, Service Industries, and the Future of Cities, Working Paper, Department of Economics, Harvard University.

Maddala, G. S. 1983. Limited-Dependent and Qualitative Variables in Econometrics. Cambridge, England: Cambridge University Press.

Porter, Michael 1998. Clusters and the New Economics of Competition, Harvard Business Review (November-December): 77-90.

Rosenthal, Stuart and William Strange. 2003. Evidence on the Nature and Sources of Agglomeration Economics. In Handbook of Urban and Regional Economics, Volume 4, eds. V. Henderson and J.F. Thisse Amsterdam: Elsevier.

Vernon 1963. Metropolis 1985. New York: Doubleday. 
Table 1: Descriptive Statistics

\begin{tabular}{|c|c|c|c|c|c|}
\hline & Mean & Standard Deviation & Minimum & Maximum & Number of Observations \\
\hline \multicolumn{6}{|l|}{ Full Data Set } \\
\hline Log(Programmers in Organization+1) & 1.7382 & 2.2898 & 0 & 8.5535 & 86,879 \\
\hline $\log ($ Programmers in Establishment +1$)$ & 0.5100 & 1.0189 & 0 & 6.2166 & 86,879 \\
\hline Organizational Capability Factor & 0 & 1 & -0.4433 & 5.9924 & 86,879 \\
\hline Establishment Capability Factor & 0 & 1 & -0.3768 & 44.6452 & 86,879 \\
\hline MSA Population over 500,000 Dummy & 0.7371 & 0.4402 & 0 & 1 & 86,879 \\
\hline Multi-Establishment Firm Dummy & 0.4479 & 0.4973 & 0 & 1 & 86,879 \\
\hline Log(Establishment Employment) & 5.3376 & 0.7248 & 4.605 & 10.933 & 86,879 \\
\hline CEI & 0.2436 & 0.4293 & 0 & 1 & 86,879 \\
\hline WEI & 0.1192 & 0.3240 & 0 & 1 & 86,879 \\
\hline Use an Internet Language & 0.0658 & 0.2480 & 0 & 1 & 86,879 \\
\hline Have a PC Server & 0.5513 & 0.4974 & 0 & 1 & 86,879 \\
\hline \multicolumn{6}{|l|}{ MSA Population over 500,000 } \\
\hline Log(Programmers in Organization +1$)$ & 1.7865 & 2.3393 & 0 & 8.5535 & 64,038 \\
\hline Log(Programmers in Establishment +1$)$ & 0.5606 & 1.0899 & 0 & 6.2166 & 64,038 \\
\hline Organizational Capability Factor & -0.0100 & 0.9578 & -0.4433 & 5.9924 & 64,038 \\
\hline Establishment Capability Factor & 0.0385 & 1.0877 & -0.3768 & 44.6452 & 64,038 \\
\hline \multicolumn{6}{|l|}{ Other areas } \\
\hline Log(Programmers in Organization +1$)$ & 1.6029 & 2.1393 & 0 & 8.5535 & 22,841 \\
\hline Log(Programmers in Establishment +1$)$ & 0.3682 & 0.7691 & 0 & 6.2166 & 22,841 \\
\hline Organizational Capability Factor & 0.0281 & 1.1094 & -0.4433 & 5.9924 & 22,841 \\
\hline Establishment Capability Factor & -0.1080 & 0.6861 & -0.3768 & 36.7297 & 22,841 \\
\hline \multicolumn{6}{|l|}{ Single Establishment Firms } \\
\hline Log(Programmers in Establishment +1$)$ & 0.5330 & 0.9668 & 0 & 6.2166 & 47,966 \\
\hline Establishment Capability Factor & -0.0347 & 0.8381 & -0.3768 & 36.7297 & 47,966 \\
\hline \multicolumn{6}{|l|}{ Multi-Establishment Firms } \\
\hline Log(Programmers in Establishment +1$)$ & 0.4817 & 1.0791 & 0 & 6.2166 & 38,913 \\
\hline Establishment Capability Factor & 0.0428 & 1.1676 & -0.3768 & 44.6452 & 38,913 \\
\hline
\end{tabular}


Table 2: Main Results

\begin{tabular}{|c|c|c|c|c|c|c|c|c|}
\hline & \multicolumn{4}{|c|}{ Coefficients } & \multicolumn{4}{|c|}{ Marginal Effects } \\
\hline & \multicolumn{2}{|c|}{ Direct Effect Only } & \multicolumn{2}{|c|}{$\begin{array}{l}\text { Direct Effect and } \\
\text { Interaction Effect }\end{array}$} & \multicolumn{2}{|c|}{ Direct Effect Only } & \multicolumn{2}{|c|}{$\begin{array}{l}\text { Direct Effect and } \\
\text { Interaction Effect }\end{array}$} \\
\hline & $(1)$ & $(2)$ & (3) & (4) & $(5)$ & $(6)$ & (7) & $(8)$ \\
\hline & $\begin{array}{l}\text { Capability } \\
\text { Defined by } \\
\text { Programmers }\end{array}$ & $\begin{array}{l}\text { Capability } \\
\text { Defined by } \\
\text { Factors }\end{array}$ & $\begin{array}{l}\text { Capability } \\
\text { Defined by } \\
\text { Programmers }\end{array}$ & $\begin{array}{l}\text { Capability } \\
\text { Defined by } \\
\text { Factors }\end{array}$ & $\begin{array}{l}\text { Capability } \\
\text { Defined by } \\
\text { Programmers }\end{array}$ & $\begin{array}{l}\text { Capability } \\
\text { Defined by } \\
\text { Factors }\end{array}$ & $\begin{array}{l}\text { Capability } \\
\text { Defined by } \\
\text { Programmers }\end{array}$ & $\begin{array}{l}\text { Capability } \\
\text { Defined by } \\
\text { Factors }\end{array}$ \\
\hline \multirow[t]{2}{*}{ Log(Programmers in Organization+1) } & 0.0152 & & 0.0399 & & 0.0021 & & 0.0054 & \\
\hline & $(0.0057)^{* *}$ & & $(0.0082)^{* *}$ & & $(0.0008)^{* *}$ & & $(0.0011)^{* *}$ & \\
\hline \multirow[t]{2}{*}{$\log ($ Programmers in Establishment +1$)$} & 0.2670 & & 0.3395 & & 0.0361 & & 0.0457 & \\
\hline & $(0.0085)^{* *}$ & & $(0.0193) * *$ & & $(0.0012) * *$ & & $(0.0027)^{* *}$ & \\
\hline \multirow{2}{*}{$\begin{array}{l}\text { Log(Programmers in Organization+1) } \\
\text { and MSA Population }>500,000\end{array}$} & & & -0.0285 & & & & -0.0038 & \\
\hline & & & $(0.0078) * *$ & & & & $(0.0010)^{* *}$ & \\
\hline \multirow{2}{*}{$\begin{array}{l}\text { Log(Programmers in Establishment }+1) \\
\text { and MSA Population }>500,000\end{array}$} & & & -0.0804 & & & & -0.0108 & \\
\hline & & & $(0.0206)^{* *}$ & & & & $(0.0028)^{* *}$ & \\
\hline \multirow[t]{2}{*}{ Organizational Capability Factor } & & 0.0427 & & 0.0822 & & 0.0062 & & 0.0118 \\
\hline & & $(0.0102)^{* *}$ & & $(0.0192)^{* *}$ & & $(0.0015)^{* *}$ & & $(0.0028) * *$ \\
\hline \multirow[t]{2}{*}{ Establishment Capability Factor } & & 0.2091 & & 0.3823 & & 0.0303 & & 0.0550 \\
\hline & & $(0.0197)^{* *}$ & & $(0.0252) * *$ & & $(0.0029)^{* *}$ & & $(0.0037)^{* *}$ \\
\hline \multirow{2}{*}{$\begin{array}{l}\text { Organizational Capability Factor and } \\
\text { MSA Population }>500,000\end{array}$} & & & & -0.0480 & & & & -0.0069 \\
\hline & & & & $(0.0203)^{*}$ & & & & $(0.0029) *$ \\
\hline \multirow{2}{*}{$\begin{array}{l}\text { Establishment Capability Factor and } \\
\text { MSA Population }>500,000\end{array}$} & & & & -0.1847 & & & & -0.0266 \\
\hline & & & & $(0.0314) * *$ & & & & $(0.0045)^{* *}$ \\
\hline \multirow[t]{2}{*}{ MSA Population > 500,000 Dummy } & 0.0995 & 0.1308 & 0.2070 & 0.1377 & 0.0129 & 0.0180 & 0.0256 & 0.0188 \\
\hline & $(0.0180)^{* *}$ & $(0.0182)^{* *}$ & $(0.0257)^{* *}$ & $(0.0186)^{* *}$ & $(0.0022) * *$ & $(0.0024)^{* * *}$ & $(0.0029) * *$ & $(0.0024)^{* *}$ \\
\hline \multirow[t]{2}{*}{ Multi-Establishment Firm Dummy } & 0.1126 & 0.1481 & 0.1100 & 0.1464 & 0.0154 & 0.0217 & 0.0149 & 0.0213 \\
\hline & $(0.0274)^{* *}$ & $(0.0189)^{* *}$ & $(0.0273)^{* *}$ & $(0.0188) * *$ & $(0.0038)^{* *}$ & $(0.0028)^{* *}$ & $(0.0038)^{* *}$ & $(0.0028)^{* *}$ \\
\hline \multirow[t]{2}{*}{ Log(Establishment Employment) } & 0.2318 & & 0.2299 & & 0.0313 & & 0.0309 & \\
\hline & $(0.0132)^{* *}$ & & $(0.0132)^{* *}$ & & $(0.0018)^{* *}$ & & $(0.0018) * *$ & \\
\hline Observations & 86871 & 86871 & 86871 & 86871 & 86871 & 86871 & 86871 & 86871 \\
\hline LL & -24550.40 & -25914.41 & -24528.56 & -25861.03 & -24550.40 & -25914.41 & -24528.56 & -25861.03 \\
\hline
\end{tabular}

Standard errors are in parentheses. All regressions are weighted to reflect the actual geographic distribution of establishments from County Business Patterns and include dummy

variables for three-digit NAICS and month of survey. Significance levels do not change if standard errors are clustered by firm. Key results in bold.

+significant at $90 \%$ confidence level.

*significant at $95 \%$ confidence level.

**significant at $99 \%$ confidence level. 
Table 3: Are Establishment Capabilities and Organizational Capabilities Substitutes?

\begin{tabular}{|c|c|c|c|c|}
\hline & \multicolumn{2}{|c|}{$\begin{array}{l}\text { Capability Defined by } \\
\text { Programmers }\end{array}$} & \multicolumn{2}{|c|}{$\begin{array}{l}\text { Capability Defined by } \\
\text { Factors }\end{array}$} \\
\hline & $(1)$ & $(2)$ & $(3)$ & $(4)$ \\
\hline \multirow{2}{*}{ Log(Programmers in Organization+1) } & 0.0069 & 0.0089 & & \\
\hline & $(0.0006)^{* *}$ & $(0.0011)^{* *}$ & & \\
\hline \multirow[t]{2}{*}{ Log(Programmers in Establishment +1$)$} & 0.0446 & 0.0527 & & \\
\hline & $(0.0011)^{* *}$ & $(0.0024)^{* *}$ & & \\
\hline \multirow[t]{2}{*}{$\log (\text { Programmers in Organization }+1)^{*} \log ($ Programmers in Establishment +1$)$} & -0.0033 & -0.0036 & & \\
\hline & $(0.0002) * *$ & $(0.0007)^{* *}$ & & \\
\hline \multirow[t]{2}{*}{ Log(Programmers in Organization+1) and MSA Population $>500,000$} & & -0.0026 & & \\
\hline & & $(0.0011)^{*}$ & & \\
\hline \multirow[t]{2}{*}{ Log(Programmers in Establishment +1$)$ and MSA Population $>500,000$} & & -0.0098 & & \\
\hline & & $(0.0026)^{* *}$ & & \\
\hline \multirow{2}{*}{$\begin{array}{l}\text { Log(Programmers in Organization+1)* Log(Programmers in Establishment }+1) \text { and MSA } \\
\text { population }>500,000\end{array}$} & & 0.0005 & & \\
\hline & & $(0.0008)$ & & \\
\hline \multirow{2}{*}{ Organizational Capability Factor } & & & 0.0111 & 0.0144 \\
\hline & & & $(0.0016)^{* *}$ & $(0.0027) * *$ \\
\hline \multirow[t]{2}{*}{ Establishment Capability Factor } & & & 0.0335 & 0.0566 \\
\hline & & & $(0.0023)^{* *}$ & $(0.0037)^{* *}$ \\
\hline \multirow[t]{2}{*}{ Organizational Capability Factor* Establishment Capability Factor } & & & -0.0066 & -0.0084 \\
\hline & & & $(0.0013)^{* *}$ & $(0.0019) * *$ \\
\hline \multirow[t]{2}{*}{ Organizational Capability Factor and MSA Population $>500,000$} & & & & -0.0042 \\
\hline & & & & $(0.0029)$ \\
\hline \multirow[t]{2}{*}{ Establishment Capability Factor and MSA Population $>500,000$} & & & & -0.0251 \\
\hline & & & & $(0.0043) * *$ \\
\hline \multirow{2}{*}{$\begin{array}{l}\text { Organizational Capability Factor* Establishment Capability Factor and MSA population > } \\
500,000\end{array}$} & & & & 0.0023 \\
\hline & & & & $(0.0023)$ \\
\hline \multirow{2}{*}{ MSA Population > 500,000 Dummy } & 0.0174 & 0.0184 & 0.0091 & 0.0198 \\
\hline & $(0.0023)^{* *}$ & $(0.0024)^{* *}$ & $(0.0020)^{* *}$ & $(0.0030)^{* *}$ \\
\hline \multirow[t]{2}{*}{ Multi-Establishment Firm Dummy } & 0.0197 & 0.0194 & 0.0096 & 0.0095 \\
\hline & $(0.0028)^{* *}$ & $(0.0028)^{* *}$ & $(0.0028)^{* *}$ & $(0.0028) * *$ \\
\hline \multirow[t]{2}{*}{ Log(Establishment Employment) } & 0.0351 & 0.0347 & & \\
\hline & $(0.0013) * *$ & $(0.0013) * *$ & & \\
\hline Observations & 86871 & 86871 & 86872 & 86872 \\
\hline LL & -25823.42 & -25778.86 & -25199.06 & -25185.64 \\
\hline \multicolumn{5}{|c|}{$\begin{array}{l}\text { Values represent marginal effects. Standard errors are in parentheses. All regressions are weighted to reflect the actual geographic distribution } \\
\text { Business Patterns and include dummy variables for three-digit NAICS and month of survey. Key results in bold. } \\
\text { +significant at } 90 \% \text { confidence level. } \\
* \text { significant at } 95 \% \text { confidence level. } \\
* * \text { significant at } 99 \% \text { confidence level. }\end{array}$} \\
\hline
\end{tabular}


Table 4: Exploring the Exogeneity Assumptions: Robustness to Establishment-Level Decisions and Instrumental Variables

\begin{tabular}{|c|c|c|c|c|c|c|}
\hline & \multirow{2}{*}{\multicolumn{2}{|c|}{$\begin{array}{l}\text { Subset of Firms } \\
\text { Establishment-Level } \\
\text { Adoption Choices Only }\end{array}$}} & \multicolumn{4}{|c|}{ Instrumental Variables } \\
\hline & & & \multicolumn{2}{|c|}{$\begin{array}{l}\text { Instrument for Establishment } \\
\text { Capability and Organizational } \\
\text { Capability }\end{array}$} & \multicolumn{2}{|c|}{$\begin{array}{l}\text { Instrument for Establishment Capability, } \\
\text { Organizational Capability, Establishment } \\
\text { Capability*City, and Organizational } \\
\text { Capability*City }\end{array}$} \\
\hline & $(1)$ & $(2)$ & (3) & (4) & $(5)$ & $(6)$ \\
\hline & $\begin{array}{l}\text { Capability } \\
\text { Defined by } \\
\text { Programmers }\end{array}$ & $\begin{array}{l}\text { Capability } \\
\text { Defined by } \\
\text { Factors }\end{array}$ & $\begin{array}{l}\text { Capability } \\
\text { Defined by } \\
\text { Programmers }\end{array}$ & $\begin{array}{l}\text { Capability } \\
\text { Defined by } \\
\text { Factors }\end{array}$ & $\begin{array}{l}\text { Capability Defined by } \\
\text { Programmers }\end{array}$ & $\begin{array}{l}\text { Capability Defined } \\
\text { by Factors }\end{array}$ \\
\hline \multirow[t]{2}{*}{ Log(Programmers in Organization+1) } & 0.0170 & & 0.0667 & & 0.0513 & \\
\hline & $(0.0071)^{*}$ & & $(0.0351)+$ & & $(0.0187)^{* *}$ & \\
\hline \multirow[t]{2}{*}{ Log(Programmers in Establishment +1$)$} & 0.0784 & & 0.2996 & & 0.6918 & \\
\hline & $(0.0165)^{* *}$ & & $(0.1331)^{*}$ & & $(0.2454)^{* *}$ & \\
\hline \multirow{2}{*}{$\begin{array}{l}\text { Log(Programmers in Organization+1) } \\
\text { and MSA Population }>500,000\end{array}$} & -0.0169 & & -0.0443 & & -0.0309 & \\
\hline & $(0.0082)^{*}$ & & $(0.0265)+$ & & $(0.0104)^{* *}$ & \\
\hline \multirow{2}{*}{$\begin{array}{l}\text { Log(Programmers in Establishment }+1) \\
\text { and MSA Population }>500,000\end{array}$} & -0.0240 & & -0.0491 & & -0.1108 & \\
\hline & $(0.0176)$ & & $(0.1257)$ & & $(0.0904)$ & \\
\hline \multirow{2}{*}{ Organizational Capability Factor } & & 0.0186 & & 0.1579 & & 0.1509 \\
\hline & & $(0.0126)$ & & $(0.0462) * *$ & & $(0.0766)^{*}$ \\
\hline \multirow{2}{*}{ Establishment Capability Factor } & & 0.0827 & & 0.5694 & & 1.0152 \\
\hline & & $(0.0175)^{* *}$ & & $(0.1459) * *$ & & $(0.3424)^{* *}$ \\
\hline \multirow{2}{*}{$\begin{array}{l}\text { Organizational Capability Factor and } \\
\text { MSA Population }>500,000\end{array}$} & & -0.0108 & & -0.1085 & & -0.0091 \\
\hline & & $(0.0140)$ & & $(0.0384)^{* *}$ & & $(0.1589)$ \\
\hline \multirow{2}{*}{$\begin{array}{l}\text { Establishment Capability Factor and } \\
\text { MSA Population }>500,000\end{array}$} & & -0.0462 & & -0.3463 & & -0.4389 \\
\hline & & $(0.0188)^{*}$ & & $(0.1445)^{*}$ & & $(0.2114)^{*}$ \\
\hline \multirow[t]{2}{*}{ MSA Population over 500,000 Dummy } & 0.1044 & 0.0514 & 0.1894 & 0.0847 & 0.1555 & 0.0412 \\
\hline & $(0.0341)^{* * *}$ & $(0.0195)^{* *}$ & $(0.0669)^{* *}$ & $(0.0196) * *$ & $(0.0373)^{* *}$ & $(0.0347)$ \\
\hline \multirow[t]{2}{*}{ Multi-Establishment Firm Dummy } & & & 0.0481 & 0.1170 & 0.0728 & -0.1131 \\
\hline & & & $(0.0542)$ & $(0.0200) * *$ & $(0.0995)$ & $(0.1466)$ \\
\hline \multirow[t]{2}{*}{ Log(Establishment Employment) } & 0.0586 & & 0.2511 & & 0.0907 & \\
\hline & $(0.0113)^{* *}$ & & $(0.0193)^{* *}$ & & $(0.0531)+$ & \\
\hline Observations & 6708 & 6708 & 86792 & 86792 & 86792 & 86792 \\
\hline LL & -3640.56 & -3748.45 & -25551.23 & -26808.13 & -26355.95 & -26354.48 \\
\hline
\end{tabular}

Values in columns (1) and (2) represent marginal effects. These regressions are weighted to reflect the actual geographic distribution of establishments from County Business Patterns. Columns (3) through (6) show coefficients. All regressions include dummy variables for three-digit NAICS and month of survey. Standard errors are in parentheses. +significant at $90 \%$ confidence level.

*significant at $95 \%$ confidence level.

**significant at $99 \%$ confidence level. 
Table 5: Robustness to City Definitions and Different Technologies

\begin{tabular}{|c|c|c|c|c|c|c|c|c|}
\hline & \multicolumn{4}{|c|}{ Different City Definitions } & \multicolumn{4}{|c|}{$\begin{array}{c}\text { Different Technologies } \\
\text { (City is defined as MSA population }>500,000)\end{array}$} \\
\hline & \multicolumn{2}{|c|}{ Any MSA } & \multicolumn{2}{|c|}{$\begin{array}{l}\text { County Density above the Sample } \\
\text { Median ( } 610 \text { people per square mile) }\end{array}$} & \multicolumn{2}{|c|}{ Uses an Internet Language } & \multicolumn{2}{|c|}{ Has a PC Server } \\
\hline & (1) & (2) & $(3)$ & (4) & (5) & (6) & (7) & (8) \\
\hline & $\begin{array}{l}\text { Capability } \\
\text { Defined by } \\
\text { Programmers }\end{array}$ & $\begin{array}{l}\text { Capability } \\
\text { Defined by } \\
\text { Factors }\end{array}$ & $\begin{array}{l}\text { Capability } \\
\text { Defined by } \\
\text { Programmers }\end{array}$ & $\begin{array}{l}\text { Capability } \\
\text { Defined by } \\
\text { Factors }\end{array}$ & $\begin{array}{l}\text { Capability } \\
\text { Defined by } \\
\text { Programmers }\end{array}$ & $\begin{array}{l}\text { Capability } \\
\text { Defined by } \\
\text { Factors }\end{array}$ & $\begin{array}{l}\text { Capability } \\
\text { Defined by } \\
\text { Programmers }\end{array}$ & $\begin{array}{l}\text { Capability } \\
\text { Defined by } \\
\text { Factors }\end{array}$ \\
\hline \multirow{2}{*}{$\begin{array}{l}\text { Log(Programmers in } \\
\text { Organization }+1)\end{array}$} & 0.0075 & & 0.0038 & & 0.0029 & & 0.0091 & \\
\hline & $(0.0013)^{* *}$ & & $(0.0009)^{* *}$ & & $(0.0010)^{* *}$ & & $(0.0025)^{* *}$ & \\
\hline \multirow{2}{*}{$\begin{array}{l}\text { Log(Programmers in } \\
\text { Establishment }+1)\end{array}$} & 0.0475 & & 0.0399 & & 0.0289 & & 0.0986 & \\
\hline & $(0.0038)^{* *}$ & & $(0.0018)^{* *}$ & & $(0.0021)^{* *}$ & & $(0.0080)^{* *}$ & \\
\hline \multirow{2}{*}{$\begin{array}{l}\text { Log(Programmers in } \\
\text { Organization+1) and City } \\
\text { (defined in column headings) }\end{array}$} & -0.0060 & & -0.0026 & & -0.0027 & & -0.0058 & \\
\hline & $(0.0013)^{* *}$ & & $(0.0009)^{* *}$ & & $(0.0010)^{* *}$ & & $(0.0024)^{*}$ & \\
\hline \multirow{2}{*}{$\begin{array}{l}\text { Log(Programmers in } \\
\text { Establishment }+1) \text { and City } \\
\text { (defined in column headings) }\end{array}$} & -0.0122 & & -0.0056 & & -0.0043 & & -0.0272 & \\
\hline & $(0.0039)^{* *}$ & & $(0.0021)^{* *}$ & & $(0.0022)^{*}$ & & $(0.0087)^{* *}$ & \\
\hline \multirow{2}{*}{$\begin{array}{l}\text { Organizational Capability } \\
\text { Factor }\end{array}$} & & 0.0156 & & 0.0086 & & 0.0026 & & 0.0026 \\
\hline & & $(0.0035)^{* *}$ & & $(0.0020) * *$ & & $(0.0019)$ & & $(0.0041)$ \\
\hline \multirow{2}{*}{$\begin{array}{l}\text { Establishment Capability } \\
\text { Factor }\end{array}$} & & 0.0654 & & 0.0433 & & 0.0241 & & 0.1031 \\
\hline & & $(0.0055)^{* *}$ & & $(0.0029) * *$ & & $(0.0026) * *$ & & $(0.0076)^{* *}$ \\
\hline \multirow{2}{*}{$\begin{array}{l}\text { Organizational Capability } \\
\text { Factor and City (defined in } \\
\text { column headings) }\end{array}$} & & -0.0106 & & -0.0043 & & -0.0037 & & -0.0078 \\
\hline & & $(0.0036)^{* *}$ & & $(0.0024)+$ & & $(0.0021)+$ & & $(0.0046)+$ \\
\hline \multirow{2}{*}{$\begin{array}{l}\text { Establishment Capability } \\
\text { Factor and City (defined in } \\
\text { column headings) }\end{array}$} & & -0.0363 & & -0.0168 & & -0.0107 & & -0.0575 \\
\hline & & $(0.0062)^{* *}$ & & $(0.0041)^{* *}$ & & $(0.0028)^{* *}$ & & $(0.0101)^{* *}$ \\
\hline \multirow{2}{*}{$\begin{array}{l}\text { City (defined in column } \\
\text { headings) }\end{array}$} & 0.0285 & 0.0183 & 0.0215 & 0.0189 & 0.0138 & 0.0117 & 0.0092 & -0.0104 \\
\hline & $(0.0032)^{* *}$ & $(0.0028)^{* *}$ & $(0.0030)^{* *}$ & $(0.0023) * *$ & $(0.0033)^{* *}$ & $(0.0025)^{* *}$ & $(0.0081)$ & $(0.0057)+$ \\
\hline \multirow{2}{*}{$\begin{array}{l}\text { Multi-Establishment Firm } \\
\text { Dummy }\end{array}$} & 0.0149 & 0.0214 & 0.0153 & 0.0222 & -0.0114 & -0.0079 & -0.0433 & -0.0235 \\
\hline & $(0.0038)^{* *}$ & $(0.0028)^{* *}$ & $(0.0038)^{* *}$ & $(0.0028) * *$ & $(0.0030)^{* *}$ & $(0.0023) * *$ & $(0.0074) * *$ & $(0.0054)^{* *}$ \\
\hline \multirow{2}{*}{$\begin{array}{l}\text { Log(Establishment } \\
\text { Employment })\end{array}$} & 0.0310 & & 0.0311 & & 0.0076 & & 0.0460 & \\
\hline & $(0.0018)^{* *}$ & & $(0.0018)^{* *}$ & & $(0.0016)^{* *}$ & & $(0.0041)^{* *}$ & \\
\hline Observations & 86871 & 86871 & 86871 & 86871 & 86871 & 86871 & 86877 & 86877 \\
\hline LL & -24531.22 & -25868.97 & -24530.10 & -25848.86 & -18589.44 & -19338.25 & -54902.83 & -55637.69 \\
\hline
\end{tabular}

Values represent marginal effects. Standard errors are in parentheses. All regressions are weighted to reflect the actual geographic distribution of establishments from County

Business Patterns and include dummy variables for three-digit NAICS and month of survey.

+significant at $90 \%$ confidence level. *significant at $95 \%$ confidence level. **significant at $99 \%$ confidence level. 
Table 6: Robustness to Competition

\begin{tabular}{|c|c|c|c|c|}
\hline \multirow{2}{*}{-2} & \multicolumn{2}{|c|}{$\begin{array}{l}\text { Competition defined by number of } \\
\text { establishments in same six-digit NAICS } \\
\text { and the same county }\end{array}$} & \multicolumn{2}{|c|}{$\begin{array}{l}\text { Competition defined by total } \\
\text { employment in same six-digit NAICS } \\
\text { and the same county }\end{array}$} \\
\hline & $(1)$ & $(2)$ & $(3)$ & $(4)$ \\
\hline \multirow{2}{*}{$\begin{array}{l}\text { Log(Programmers in } \\
\text { Organization }+1)\end{array}$} & 0.0062 & & 0.0064 & \\
\hline & $(0.0012)^{* *}$ & & $(0.0014) * *$ & \\
\hline \multirow{2}{*}{$\begin{array}{l}\text { Log(Programmers in } \\
\text { Establishment }+1)\end{array}$} & 0.0452 & & 0.0484 & \\
\hline & $(0.0028)^{* *}$ & & $(0.0033)^{* *}$ & \\
\hline \multirow{2}{*}{$\begin{array}{l}\text { Log(Programmers in } \\
\text { Organization }+1) \text { and MSA } \\
\text { Population }>500,000\end{array}$} & -0.0026 & & -0.0033 & \\
\hline & $(0.0012)^{*}$ & & $(0.0011)^{* *}$ & \\
\hline \multirow{2}{*}{$\begin{array}{l}\text { Log(Programmers in } \\
\text { Establishment }+1) \\
\text { and MSA Population }>500,000\end{array}$} & -0.0114 & & -0.0094 & \\
\hline & $(0.0030)^{* * *}$ & & $(0.0029)^{* *}$ & \\
\hline \multirow[t]{2}{*}{ Organizational Capability Factor } & & 0.0132 & & 0.0148 \\
\hline & & $(0.0030)^{* *}$ & & $(0.0038) * *$ \\
\hline \multirow[t]{2}{*}{ Establishment Capability Factor } & & 0.0518 & & 0.0501 \\
\hline & & $(0.0043) * *$ & & $(0.0067)^{* *}$ \\
\hline \multirow{2}{*}{$\begin{array}{l}\text { Organizational Capability Factor } \\
\text { and MSA Population }>500,000\end{array}$} & & -0.0047 & & -0.0053 \\
\hline & & $(0.0031)$ & & $(0.0029)+$ \\
\hline \multirow{2}{*}{$\begin{array}{l}\text { Establishment Capability Factor } \\
\text { and MSA Population > 500,000 }\end{array}$} & & -0.0301 & & -0.0276 \\
\hline & & $(0.0056)^{* *}$ & & $(0.0052) * *$ \\
\hline \multirow{2}{*}{$\begin{array}{l}\text { Log(Programmers in } \\
\text { Organization }+1) \text { and } \\
\text { Competition (defined in column } \\
\text { headings) }\end{array}$} & -0.0006 & & -0.0002 & \\
\hline & $(0.0003)^{*}$ & & $(0.0002)$ & \\
\hline \multirow{2}{*}{$\begin{array}{l}\text { Log(Programmers in } \\
\text { Establishment }+1) \text { and } \\
\text { Competition (defined in column } \\
\text { headings) }\end{array}$} & 0.0003 & & -0.0006 & \\
\hline & $(0.0006)$ & & $(0.0004)$ & \\
\hline \multirow{2}{*}{$\begin{array}{l}\text { Organizational Capability Factor } \\
\text { and Competition (defined in } \\
\text { column headings) }\end{array}$} & & -0.0010 & & -0.0007 \\
\hline & & $(0.0007)$ & & $(0.0005)$ \\
\hline \multirow{2}{*}{$\begin{array}{l}\text { Establishment Capability Factor } \\
\text { and Competition (defined in } \\
\text { column headings) }\end{array}$} & & 0.0022 & & 0.0009 \\
\hline & & $(0.0015)$ & & $(0.0011)$ \\
\hline \multirow{2}{*}{$\begin{array}{l}\text { MSA Population over 500,000 } \\
\text { Dummy }\end{array}$} & 0.0214 & 0.0170 & 0.0222 & 0.0167 \\
\hline & $(0.0034) * *$ & $(0.0026) * *$ & $(0.0032) * *$ & $(0.0025)^{* *}$ \\
\hline \multirow{2}{*}{$\begin{array}{l}\text { Multi-Establishment Firm } \\
\text { Dummy }\end{array}$} & 0.0147 & 0.0212 & 0.0147 & 0.0211 \\
\hline & $(0.0038)^{* * *}$ & $(0.0028)^{* *}$ & $(0.0038)^{* *}$ & $(0.0028)^{* *}$ \\
\hline \multirow[t]{2}{*}{ Log(Establishment Employment) } & 0.0308 & & 0.0307 & \\
\hline & $(0.0018)^{* * *}$ & & $(0.0018) * *$ & \\
\hline \multirow{2}{*}{$\begin{array}{l}\text { Competition (defined in column } \\
\text { headings) }\end{array}$} & 0.0029 & 0.0013 & 0.0018 & 0.0011 \\
\hline & $(0.0010)^{* *}$ & $(0.0008)$ & $(0.0006) * *$ & $(0.0005)^{*}$ \\
\hline Observations & 86871 & 86871 & 86871 & 86871 \\
\hline LL & -24517.55 & -25837.67 & -24522.48 & -25847.11 \\
\hline
\end{tabular}

Values represent marginal effects. Standard errors are in parentheses. All regressions are weighted to reflect the actual geographic distribution of establishments from County Business Patterns and include dummy variables for three-digit NAICS and month of survey.

+significant at $90 \%$ confidence level.

*significant at $95 \%$ confidence level.

$* *$ significant at $99 \%$ confidence level. 
Figure 1: How Internal Capabilities and Local Resources Influence Adoption

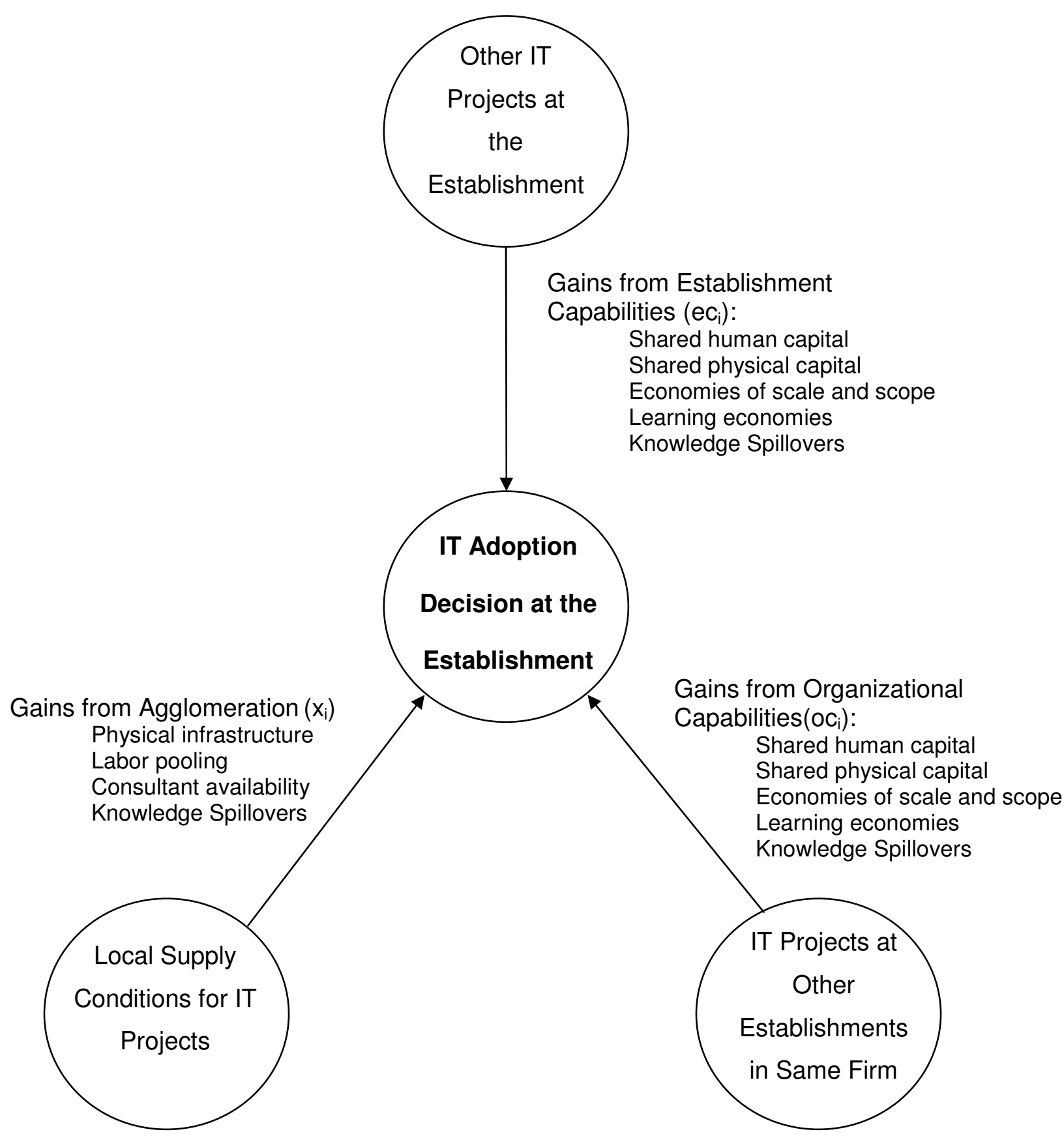




\section{Figure 2a: Adoption Probability by Organizational Capabilities}

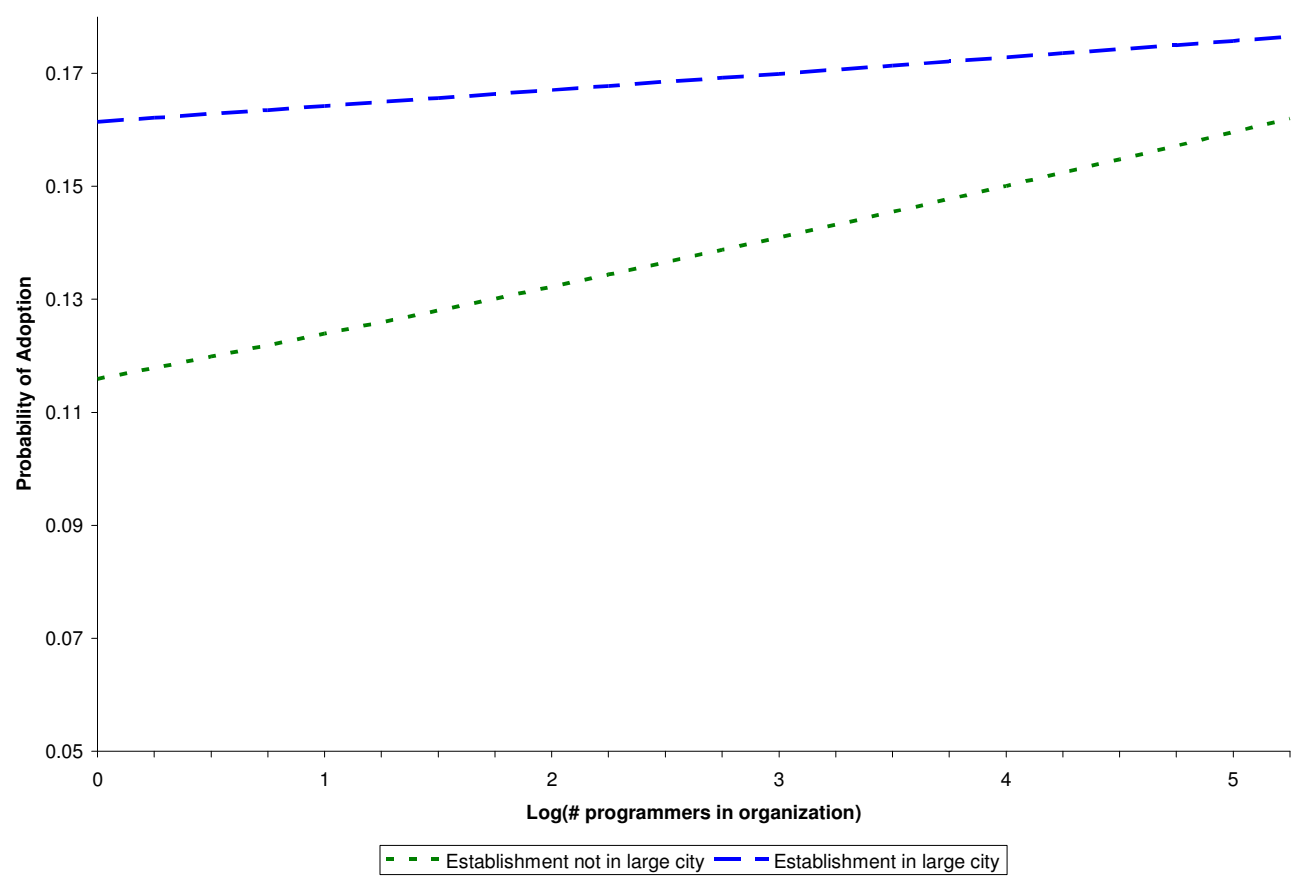

\section{Figure 2b: Adoption Probability by Establishment Capabilities}

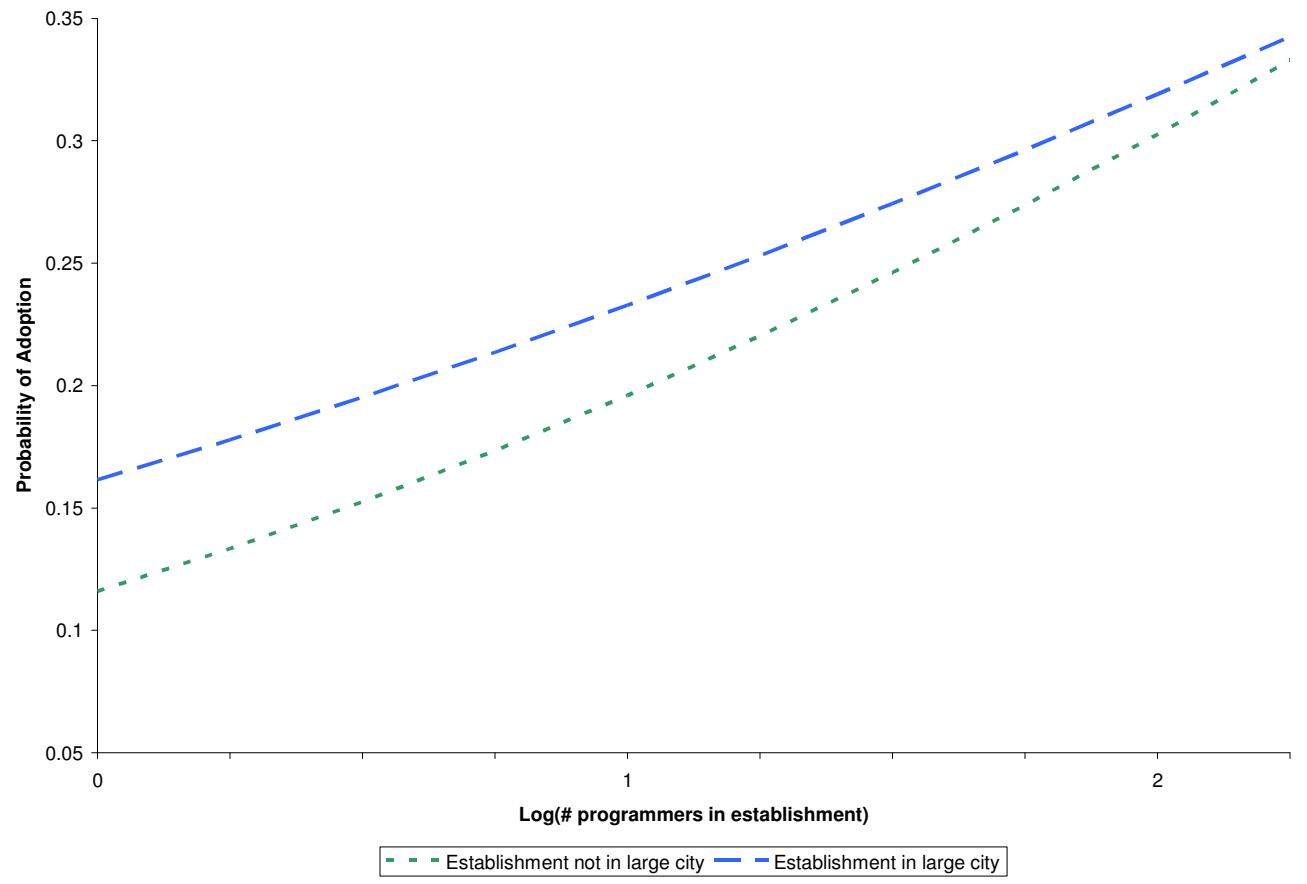

Predictions are based on a representative firm in the second half of 2000 with mean values of employment, industry effects, and multi-establishment status. Figure $2 \mathrm{a}$ assumes establishment capabilities are zero. Figure $2 \mathrm{~b}$ assumes organizational capabilities are zero. 